\title{
TCOM \\ Citizen science and the professional-amateur divide: lessons from differing online practices
}

\section{Liz Dowthwaite and James Sprinks}

\begin{abstract}
Online citizen science platforms increasingly provide types of infrastructural support previously only available to organisationally-based professional scientists. Other practices, such as creative arts, also exploit the freedom and accessibility afforded by the World Wide Web to shift the professional-amateur relationship. This paper compares communities from these two areas to show that disparate practices can learn from each other to better understand their users and their technology needs. Three major areas are discussed: mutual acknowledgement, infrastructural support, and platform specialisation. We discuss the advantages and disadvantages of differing practices, and lessons that can be learnt for online citizen science platforms.
\end{abstract}

Keywords

DOI

Introduction
Citizen science; Public engagement with science and technology

https://doi.org/10.22323/2.18010206

Submitted: 27th March 2018

Accepted: 14th September 2018

Published: 17th January 2019

Digital technologies increasingly provide the kinds of infrastructural support previously only available to the organisationally-based professional, allowing amateurs to expand their practices. Social media technologies, alongside accessible professional tools, have become essential for gaining exposure, income and feedback for work. Opportunities for networking between amateurs, professionals, and the public can also initiate unique collaborative projects. Online citizen science platforms, through their design and access to scientific data and analyses, are changing the landscape of the professional-amateur divide in science and research, with volunteers able to contribute towards the formal scientific process without the normally required accreditation. Researchers must consider how such digital technologies remove or blur barriers to professional practice, and how this affects the experience of different types of user.

Citizen science allows professional scientist to both provide information to and receive information from amateurs, who many see as volunteer participants in research; technology allows the practice to challenge traditional forms of science 
activity through permitting collective participation, less-mediated sharing of results and potential co-production of knowledge [Johnston, Franks and Whitelaw, 2017]. Citizen science is by no means the only approach that has exploited the freedom and accessibility afforded by the World Wide Web to shift the professional-amateur relationship. The creative industries have been utilising online platforms for years, allowing users to publish work without the need for professional intermediaries, to interact and collaborate with others, experiment with new types of work and formats, and to promote their work and reach wider audiences. This paper compares the practices of one particular online creative community (webcomics) with current practices in citizen science, showing how each are engaging with digital technologies in different ways to complicate and blur the professional-amateur divide. As a contribution to continuing discussions about amateur practice, this paper also draws attention to the changing attitudes and approaches of the professional in both of these communities, and what this means for the amateur in terms of new opportunities to gain recognition for their practice. Disparate practices can learn from each other in order to better understand their range of users and improve the design of technologies in ways that are appropriate to their needs, and this paper finishes by considering implications for future research and working practices.

\section{Background}

Traditionally, aside from making money from their work, the professional is considered as distinct from the amateur in that they share a strong sense of identity with colleagues, use institutionalised means to validate their own and others training, and are recognised by the public for their specialist knowledge, experience or technique [Kaplan, 1960]. Many professionals now also embrace the freedoms offered by online services, becoming 'digital nomads' who are not constrained to a fixed workplace infrastructure or schedule and use digital technologies to achieve the same level of contact, control and communication as the office [Makimoto and Manners, 1997]. Amateurs can maintain a broader knowledge of a field whilst professionals may focus on one particular area to make their living. Professionals set standards for excellence by which amateurs orient themselves, and amateurs reciprocate by offering advice and support as an experienced audience [Ploderer, Howard and Thomas, 2010]. There is, therefore, an important interdependent relationship between professionals and amateurs [Stebbins, 1992]. There has been an increase in interest in recent years in amateur practice, especially online, for example how users become digital producers, editors and curators [Lessig, 2009; Lessig, 2012; Roibás and Sala, n.d.], and how DIY and 'expert amateur' communities work [Kuznetsov and Paulos, 2010; Leyshon et al., 2005; Tanenbaum et al., 2013]. Amateur communities develop their expertise collectively by critiquing and learning from each other's work [Kuznetsov and Paulos, 2010; Torrey, Churchill and McDonald, 2009], forming support networks that often mirror some of the benefits of the professional institution. The public also plays a role by offering financial support and feedback. In this Professional-Amateur-Public triad, the public can become amateurs, amateurs may turn professional, and professionals often re-enter the amateur community when they retire (Figure 1).

The transition between amateur and professional status has become blurred due to increased access to tools, markets, and information through online technology, and particularly due to online interaction between the two groups. This has resulted in the emergence of the professional amateur, or 'Pro-Am', bridging the professional 
Support and Feedback

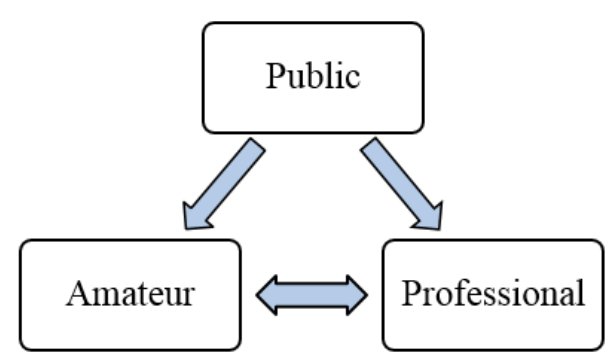

Production of Work

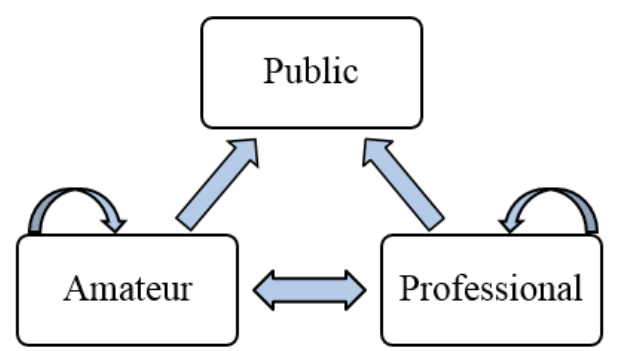

Career Progression

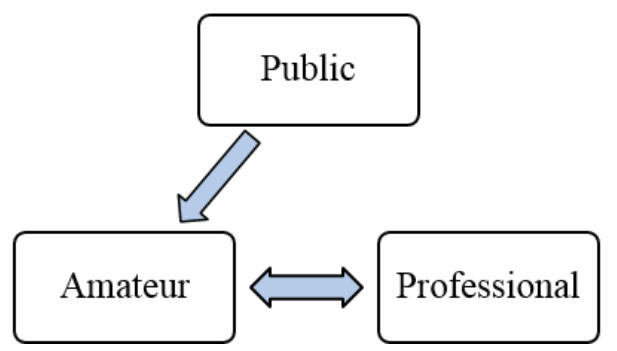

Figure 1. Examples of relationships in the Public-Amateur-Professional triad.

and amateur divide through their activities online, creating new knowledge streams, new ways of working, and new organisational structures [Leadbeater and Miller, 2004]; these include pre-professionals, semi-professionals, and post-professionals, and are prevalent across many domains, for example open-source software, astronomy [Penston, 2001], music [Hoare et al., 2014; Strachan, 2007], journalism [Nicey, 2016] and even metal detecting [Dobat and Jensen, 2016]. Despite lacking the infrastructural support offered to the traditional professional, such amateurs are enabled by digital technologies to work to professional standards [Prior, 2014].

There may therefore be value in comparing the effects of working online in different practices across these differing domains, and their relative benefits and drawbacks for progression to professional acceptance. This paper addresses one such comparison, using specific case studies of individual online communities consisting of professionals and amateurs, from two different practices. It provides an overview and comparison of their practices, and discusses how lessons from the first community may be applicable to the second, and vice versa. The first community studied is from the creative industries: webcomics, a community where professionals and amateurs very much exist in the same space; findings are applied to the study of the citizen science community, where professionals have harnessed the power of amateurs to mutual gain.

These communities have been chosen for comparison because both surround predominantly desk-based activities carried out at a computer rather than involving going out into the field or to a specific venue. They also both thrive on large numbers of amateurs and professionals working in the same space. The emergence of digital technologies allowed a vast increase in the number of people able to work and participate in the creative industries in general; the same has been 
happening in the field of science, as enthusiastic amateurs are able to contribute and learn alongside professionals. Neither community would exist as they are without the Internet and this rapid increase in the use of digital technologies to facilitate working. Thirdly, both webcomics and citizen science appeal to a broad range of people with often highly disparate interests, and involve harnessing the human capacity for creative thinking. Inspiration for this comparison also comes from the experiences of this papers authors', who noticed striking similarities in the way both communities discussed their interactions online during several years immersed in the respective communities [see for example Dowthwaite, 2015; Sprinks et al., 2015]. Whilst motivations for participation may differ (although curiosity and interest in a variety of topics and opportunities for learning rank highly in both communities), other aspects of their practice are likely to overlap in interesting ways.

\section{Webcomics}

Webcomics, online comics produced by an independent creator with no corporate sponsorship [Fenty, Houp and Taylor, 2004], are found all over the internet, freely accessible to readers in all genres. In the past, due to the costs of production and distribution, a comic artist had no choice but to work with a publisher, and the artist's work would be passed on to colourists, editors, publishers, printers, and distributors [McCloud, 2000]. The underground self-published Comix of the 1960s began to challenge this, and in the digital age self-publication expanded to the Internet. Lower costs, access to large audiences unbounded by geography, and the ability to retain creative control, mean that webcomics are a viable alternative to traditional print for aspiring artists [Fenty, Houp and Taylor, 2004; Guigar et al., 2011]. The majority of webcomics creators are amateurs who cannot support themselves financially through their work. However, there are an increasing number of creators who take up webcomics as full-time professional work, often through selling merchandise online. It is often unclear whether a popular creator is a professional or not; most likely they fall somewhere in between. Many amateur webcomics creators demonstrate the commitment, talent, and resources of professional creators but not the income. Professional and amateur webcomic creators exist in the same space, using the same methods to share work and build readerships. Besides production, distribution, and merchandise, creators make wide use of other opportunities provided by the internet. The ability to comment on comics, discuss work, and share content through social media allows creators to engage with each other as well as with fans [Dowthwaite, Houghton and Mortier, 2015; Rohac, 2010].

\section{Citizen science}

Citizen science, also known as "public participation in scientific research" [Hand, 2010], can be described as research conducted, in whole or in part, by amateur or nonprofessional participants often through crowdsourcing techniques. The internet in particular has allowed amateurs to contribute large quantities of data to scientific research remotely in the comfort of their own home [Bonney et al., 2009], increasing citizen science participation in terms of numbers if not diversity [Newman et al., 2012]. One method by which citizen science websites utilise amateur researchers is through using Virtual Citizen Science (VCS) platforms. The participant acts as the analyst, usually studying previously collected and remotely sensed data by the professional research community displayed to them through a 
website interface [Reed, Rodriguez and Rickhoff, 2012]. Volunteers have complex motivations for participating, including contributing to science, learning and research, and for their own interest, and researchers are discovering new ways of engaging users through design and interaction [Jackson et al., 2016; Raddick et al., 2013; Tiago et al., 2017; Wiggins and Crowston, 2011; Woodcock et al., 2017].

Often amateurs gain a deep understanding of the individual projects they work on and develop a thinking process similar to the expert [Trumbull et al., 2000], allowing them to learn about scientific fields they are interested in [Masters et al., 2016] and contribute additional work outside of the tasks they are asked to do. For example, one user created a flowchart of every glitch type in Gravity Spy (see http:/ / studiosilverlight.com/GravitySpyGlitchLibrary.html), a project which helps the scientists at LIGO (Laser Interferometer Gravitational-Wave Observatory) to improve the detection of gravitational waves [Zevin et al., 2017]. Other users carry out their own investigations and post questions and results on project forums. However, working as a crowd on more complex tasks that would usually be taken on by professionals, for example paper writing, still faces strong barriers due to knowledge gaps surrounding the scientific process [Crowston, Mitchell and Østerlund, 2018]. There is also still concern among some professional scientists that citizen scientists do not make real contributions to science and the only real benefits are for the public rather than the scientists [Golumbic et al., 2017]. Despite these remaining barriers, the use of online technologies to allow enthusiastic amateur scientists to contribute to data collection, and data analysis and annotation can be of real use to scientific fields in which large amounts of data are needed, and successful projects can "redefine the interactions between practicing amateurs and professionals." [Johnston, Franks and Whitelaw, 2017].

\section{Methods}

In Study One, semi-structured interviews were carried out with 6 professional and 5 amateur webcomic artists at the largest gathering of independent comic creators in the U.K. All webcomics creators listed as attending the convention were contacted via email and invited to take part in the study. 'Webcomics creator' was taken to mean any creator who currently or has in the past published comics online, which were available to read for free and were designed to be put online in the first instance (this does not therefore include printed comics that were uploaded online at a later time). This resulted in 19 positive responses, of which 11 interviews were completed due to time constraints. Interviews lasted between 10 and 40 minutes and were carried out at the display tables of each creator, with the exception of one creator whose interview was completed after the event, at a location close to her home and work. The interviews were guided by the creators in order to fully cover any issues they wished to bring up, but broadly all the interviews covered: the use of social media with regards to their comics work, concerns and negative experiences; awareness of site policies and IP rights; and using online services for monetisation. The open-ended approach to interviewing allows researchers to respond to interesting topics that may naturally emerge, and allows new ideas to be developed and hypotheses to emerge [Oppenheim, 2000]. All of the interviews were audio-recorded and notes were taken. They were transcribed fully and analysed using an iterative, grounded approach to identify themes within the communities. The grounded method was chosen in combination with open-ended interviews in order to allow hypotheses and questions to emerge naturally [Glaser and Strauss, 1967]. The data was analysed fully by one researcher and checked by a second for agreement and consistency. 
The results from Study One highlight particular aspects of working online which allow amateur and professional webcomics creators to interact, work together, and support each other to mutual benefit. These can be grouped into three major areas that may also be interesting to citizen science communities, summarised in Table 1.

Table 1. Important areas in professional-amateur interactions identified by Study One.

\begin{tabular}{|ll|}
\hline Area & Characteristics/Behaviour \\
\hline Mutual Acknowledgement & $\begin{array}{l}\text { The perceived value of both professional and amateurs within the work- } \\
\text { ing community. The importance of 'professional' status to the community. }\end{array}$ \\
\hline Infrastructural Support & $\begin{array}{l}\text { How infrastructural support is provided by the Internet. Access to ser- } \\
\text { vices which previously were only available offline and/or to profession- } \\
\text { als. How the internet enables independence from intermediaries. }\end{array}$ \\
\hline Platform Specialisation & $\begin{array}{l}\text { How communities make use of existing tools and platforms (eg social me- } \\
\text { dia) and/or create their own more specialised platforms. The degree to } \\
\text { which websites are tailored towards specific uses, and how each com- } \\
\text { munity capitalises on them }\end{array}$ \\
\hline
\end{tabular}

In Study Two, the results from Study One were used to create a questionnaire which was distributed online to 6 projects on The Zooniverse citizen science platform; responses were collected from the professional scientist from each project who was involved in engaging with the amateur community, as this person would have the most experience of interactions between professionals and amateurs. The Zooniverse is the leading VCS platform with over 1.6 million registered users spread across the globe (Figure 2), ranging from dabblers to extremely committed volunteers [Eveleigh et al., 2014; Simpson, Page and De Roure, 2014], and each project has dedicated social media pages. The Zooniverse hosts the leading citizen science projects across a number of disciplines including astronomy, zoology, biology and history (Figure 3). The projects were chosen as representative of this broad range of disciplines, were currently live and had been so for long enough to establish interactions with users.

A questionnaire was chosen due to geographical and time constraints, but also because this allowed concentration on specific areas rather than a wider approach which was taken in study one. The questionnaire asked about which websites the scientists used for posting about their project, and how they communicate with users including how they make use of social media, and their use of real world venues to discuss their project. Finally they were asked about their overall impression of using amateurs in scientific research and how amateurs contribute to scientific research. Answers were open ended and were analysed using the themes identified in Study One. Responses that fell into each of the three themes were extracted to produce three collections of responses which were then individually analysed for their content. This was then contrasted with the content of the responses from study one, as laid out in the Discussion.

Results

In Study One, the webcomic community, consisting of readers and fans, amateurs, and professionals, was highly valued by those interviewed; reasons for this included promotion, trading information, advice and support, cultivating a readership, and flagging up issues of copyright and other problems. All those interviewed use social media extensively. They all use Twitter, and most use Facebook 


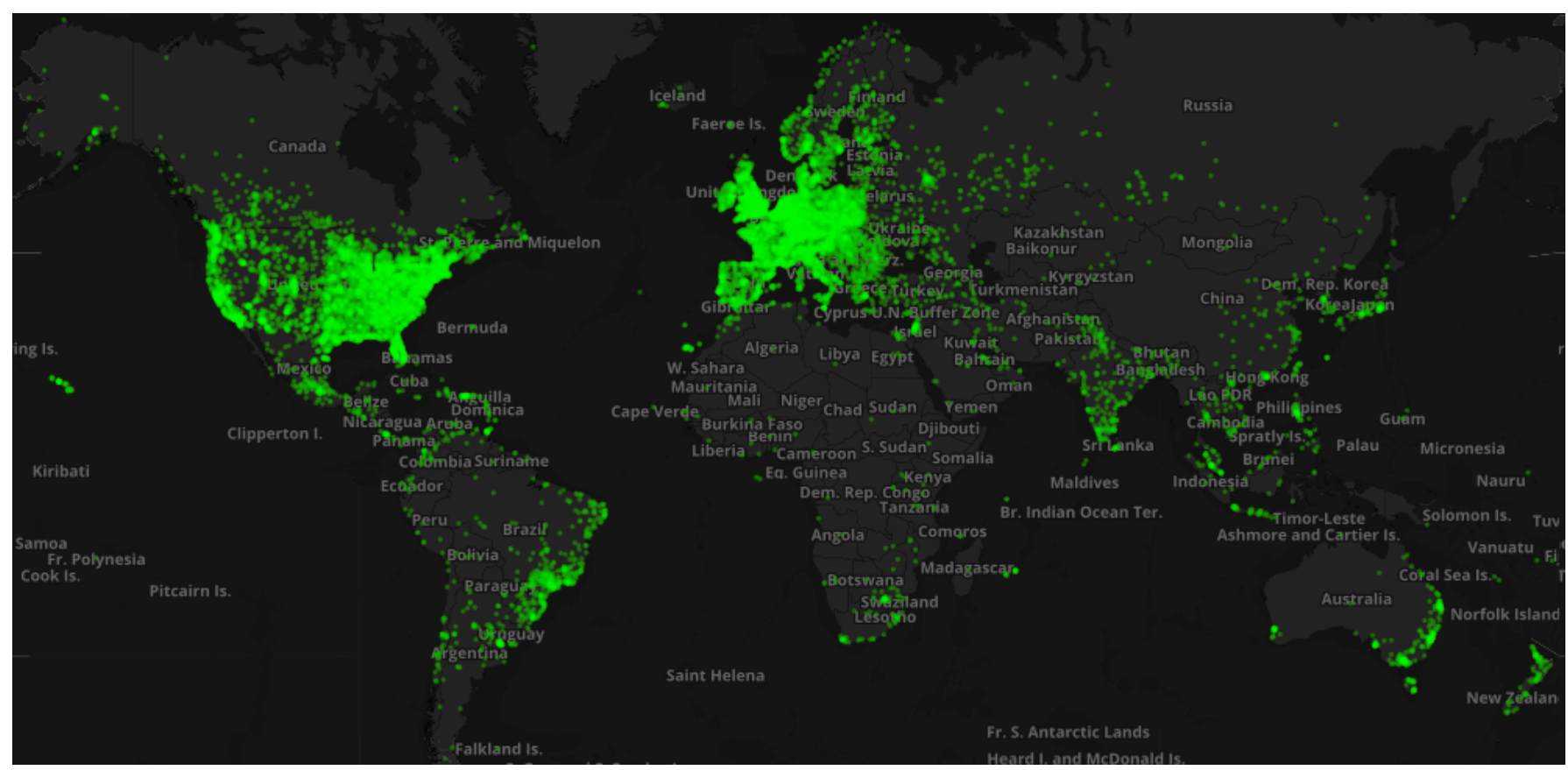

Figure 2. Global map of where the first million Zooniverse (www.zooniverse.org) citizen science volunteers are based [Simpson, Page and De Roure, 2014].

(7) and Tumblr (8). They all also publish their comics on homepages, but most two-way interaction occurs through social media. The results highlight particular aspects of working online which allow amateur and professional webcomics creators to interact, work together, and support each other to mutual benefit. The results from the three themes described in the method are summarised in Table 2.

Table 2. Important areas in professional-amateur interactions within the webcomics community.

\begin{tabular}{|ll|}
\hline Area & Webcomics Characteristics \\
\hline Mutual Acknowledgement & $\begin{array}{l}\text { Professionals and amateurs are seen as equals in interactions, and it is } \\
\text { not seen as important whether a creator is a professional or not. Both } \\
\text { professional and amateur creators share work, advice, and support. }\end{array}$ \\
\hline Infrastructural Support & $\begin{array}{l}\text { Amateurs and professionals benefit from infrastructural support } \\
\text { provided by the Internet. Access to services such as independent pub- } \\
\text { lishing, distribution, and promotion allow amateurs an opportunity to } \\
\text { achieve similar goals as professionals. }\end{array}$ \\
\hline Platform Specialisation & $\begin{array}{l}\text { Webcomics tend to have specific homepages, and still need to drive } \\
\text { viewers to websites to sell merchandise, but the emphasis for interac- } \\
\text { tion within the communities is on social media and more general online } \\
\text { spaces. }\end{array}$ \\
\hline
\end{tabular}

In Study Two, the overall impression of using amateurs in scientific research was very positive, both in terms of the knowledge brought and the data collected. The scientists frequently use the major social media sites, with all of those surveyed using Facebook and some using Twitter (4), Google+ (3), and personal blogs (2). The results in terms of the three areas identified in study one are summarised in Table 3. 


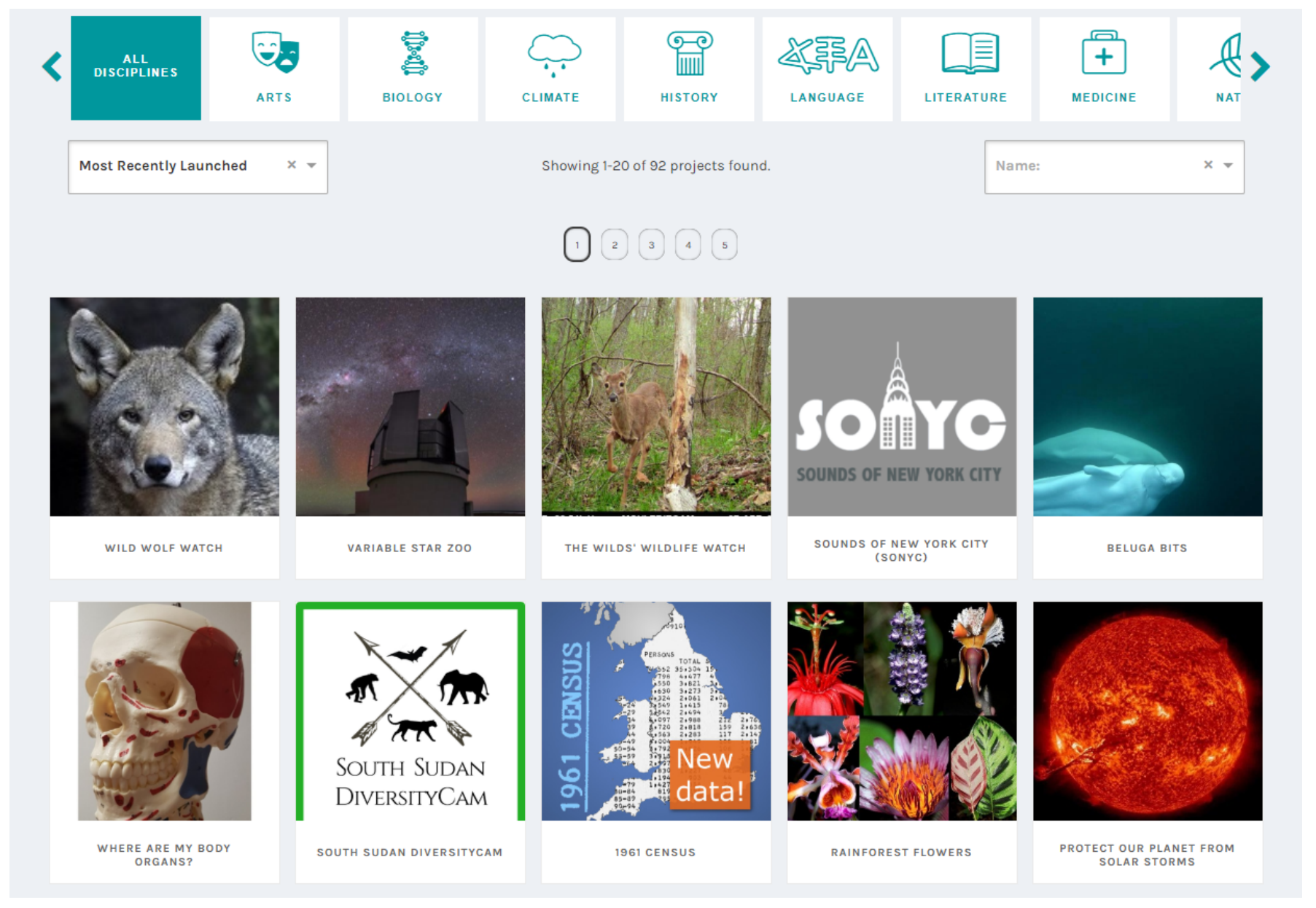

Figure 3. Selection of Zooniverse projects across a range of scientific disciplines (www.zooniverse.org/projects).

Table 3. How the three areas identified in study 1 relate to interactions between professionals and amateurs in citizen science.

\begin{tabular}{|ll|}
\hline Area & Citizen Science Characteristics \\
\hline Mutual Acknowledgement & $\begin{array}{l}\text { Amateurs are beginning to gain acknowledgement from professionals, } \\
\text { and in a few cases this has led to more direct collaboration. Professionals } \\
\text { recognise the value of amateur scientists. }\end{array}$ \\
\hline Infrastructural Support & $\begin{array}{l}\text { Established professionals govern and reproduce aspects of professional } \\
\text { scientific infrastructure. Although amateurs are beginning to gain pub- } \\
\text { lishing credit, qualifications and accreditation are still required to gain } \\
\text { access to the full scientific process. }\end{array}$ \\
\hline Platform Specialisation & $\begin{array}{l}\text { Citizen science restricts the majority of interaction to specialised plat- } \\
\text { forms, in order for professionals to control data output and analysis. So- } \\
\text { cial media use is mostly one-way, for promotion and dissemination. }\end{array}$ \\
\hline
\end{tabular}

\section{Mutual acknowledgment}

Mutual acknowledgement is clearly a very important factor for webcomics creators. Most felt that social media was vital to their work, as "a way of building engagement with the audience" (W3), as well as to form networks of professional and amateur artists who provide advice and encouragement, and who "support each 
other when things go wrong, but also when things go right" (W8). Both amateurs and professionals see great value in forming online networks of creators who can provide advice, support, and encouragement and every stage of a career. This is particularly important for creators who work alone, and do not have the benefits of offline interactions with others in their chosen career. Working online also means that amateur and professional work can be judged at the same level, allowing creators to gain popularity on their own creative merits. This can however lead to misconceptions about how easy it is to make money from webcomics: "three years in and it's like oh actual minimum wage!" (W6).

For the citizen scientists, acknowledgement is also important, but it is more formalised recognition of the good work of the amateur scientists from the professionals. The scientists felt that input from amateur citizen scientists had a positive impact: "We have over 70 published papers so far and many new scientific (and occasionally non-scientific) discoveries..." (C4), and attitudes towards the amateur scientists themselves were extremely positive: "Their combined quality is excellent, and there are also some cases where individuals have become involved and trained enough to contribute significantly outside the platform classifications..." (C3). The results suggest that the gap between expert and amateur is narrowing: "My most recent paper, for example, lists a volunteer as one of the co-authors because he did some work verifying redshifts that was very good quality." (C3); "I view them as collaborators, and I take the approach of trying to include them in the process of getting from data reduction to analysis to the submitted and hopefully published paper." (C4). Also demonstrated by these results is how experts' engagement with the amateur community has grown; where in early citizen science projects experts would use the community as a crowd to reduce large amounts of data, they are now collaborating on analysis with smaller groups and even viewing certain amateurs as co-authors on scientific output. However, the contribution of citizen scientists often still goes unrecognised, and so it is important that acknowledgement of their efforts through engagement and more formally through publication continues. This can ensure they benefit from understanding the research process, its outcomes, and the broader impacts that could arise [Cooper, Shirk and Zuckerberg, 2014].

\section{Infrastructural support}

For webcomics, the workflow is the same for professionals and amateurs: they create comics, and put them online immediately for the consumer. There is no longer a need to go through a traditional publisher or distribution company, giving much greater freedom to succeed. Creators can also experiment with different ways of making money and publish in a way that is best for them, becoming professionals on their own terms. Existing professionals illustrate this by having done it themselves - such a career would have been impossible a few short years ago - and by providing advice and encouragement to others. The greater power provided to artists to make their own decisions and run their own comics, particularly as a career, was summarised by one particular creator: "We can create materials, books, which we couldn't otherwise afford, and get to retain complete control over our property and the presentation thereof. If a publisher does come calling, it allows us to ask the bigger question of 'what can you actually do for me that I can't do myself' which ten-plus years ago was unthinkable. Consequently, we no longer need to give away the lion's share of profit to someone who had very little to do with the production of the piece." 
(W11). However, it takes many years of building up recognition before monetisation can be attempted, and creators often appear to have made their own personal 'infrastructure': "you have to be a business person" (W9). This dedication echoes the traditional working day of offline industries.

In citizen science, it is still the expectation that projects are led by scientists with established track records in a peer-recognised institution, and amateurs are usually only involved for a very small part of the project. The projects themselves are usually run through a funded research project at a professional institution.

However, the value of input from amateur scientists without this formal training is increasingly recognised. Regarding data quality, C2 explains: "Many ecologists have concerns about the quality of CS [citizen science] processed data. [...] The quality of citizen-scientist processed data far exceeded my expectations [...] validation indicates users achieve about $97 \%$ accuracy rates, which is pretty damn good if you ask me."

Whilst the use of social media and blogs in presenting the outputs of citizen science work is increasing, this also still relies heavily on infrastructural support. In order to promote the platforms and scientific results to other professionals, scientific journal articles and conferences are used: "I've presented at several science conferences. Papers on these results have either been published or are in progress" (C5); "I've performed guest lectures in other ecology/biology departments..." (C2). The amateurs are then informed about these papers in blog posts and newsletters. However, projects are also presented at outreach events, ranging from presentations at local schools and amateur science clubs to attendance at 'citizen science conferences', which the general public are actively encouraged to attend: "I also visit schools and amateur astronomy clubs to give presentations." (C3).

\section{Platform specialisation}

Webcomics tend to have their own homepages, particularly those more towards the professional end of the scale, and when webcomics were in their infancy, artists used link to other artists on their own webpages. This behaviour has now moved to social media, where the reach is much greater, and emphasis for interaction within the communities is also on these platforms. Through social media, creators who are just starting out get noticed, shared, and followed by people who are further along, and also by those in traditional publishing. This allows webcomics to reach audiences that might not otherwise seek them out, as they show up in newsfeeds and are shared by fans with their friends. However, creators were very aware of some of the downsides to both working on the internet and using social media: "like anything else in comics, to really make money from it you have to work it and treat it like a job" (W2). The vast number of webcomics online at any time mean that talented creators can get lost in the flood of content and may not achieve the audiences they would otherwise. They have to maintain a constant awareness of and presence across many platforms to gain the audiences they desire: "I need as many people as I can to see my work" (W8); "It changes every year which are the main ones, and which are the best ones, and you just have to kind of stay on top of it" (W10). On social media they also have to compete with other content generators as well as the flood of news, ads, memes, and interactions between friends that characterise the platforms: "I don't think I can compete with the constant churn of social media" (W9). 
Creators also still need to drive viewers to their websites to sell merchandise and make money from sponsors and advertising. There are an increasing number of platforms specifically for selling merchandise (e.g. Topatoco) as well as those that publish many webcomics in one place (e.g. Hiveworks). These sites remove some of the stresses of maintaining a website whilst continuing to provide a personalised home for the comic. However, creators also pointed out that there is still no guarantee of making money from their work: "You have to become very very very popular in order to make a living" (W9).

Due to the need for the professional scientific community to maintain control over the analysis tasks amateurs undertake, and the data they perform these tasks on, specially developed platforms are utilised for each citizen science project. The majority of communication through social media is one-way, to build interest and present science results to the amateur community rather than to encourage interaction: "I use social media to raise awareness $\mathcal{E}$ maintain interest in the platform; ... and Facebook to post cool photos or stories." (C2). Citizen science platforms incorporate discussion forums for two-way communication, to keep users on the platform so they can continue to work on the science cases, whilst also taking part in discussions and interacting with other amateurs and professionals in the fields that interest them. The majority of projects surveyed do use their specific blogs and discussion forums: "I use the discussion tool websites associated with the project to communicate and post information to active volunteers" (C5). However, the majority of this communication tends to be amateur to amateur, either to discuss interesting topics or to gain support and guidance from each other regarding more difficult analysis tasks. The professional scientist will normally only interject if asked a direct question about the correct way to perform the scientific task, or a specific topic is of scientific interest.

This paper considers the results of two studies of different online communities consisting of both professionals and amateurs, to provide an overview of their practices, and to discuss how lessons from both may be applicable to the other. A key aspect of the practices and interactions taking place within each of the communities studied is the interdependent relationships between amateurs and professionals for achieving their goals. In the case of citizen scientists, an established professional community is prescribing a system of collaboration very much attuned to the existing protocols set out by the professional science community. On the other hand webcomic creators are defining their own amateurdriven industry but are increasingly supported by and able to work alongside professionals or become professional themselves. These interactions reveal key differences between these online relationships, summarised in Tables 2 and 3 above.

Although at first glance it might not seem appropriate to compare citizen science to a practice as apparently disparate as webcomics, the two communities do have similarities, such as, their reliance on digital technologies to facilitate working, and their broad appeal amongst people from a wide range of backgrounds and interests. There are also commonalities in other aspects of participation. However, their differences also provide a rare opportunity for lessons to be learnt that might not have been previously considered. The characteristics of webcomic behaviour outlined across different themes, and how they can be related to citizen science behaviour provides insight into new ways of utilising citizen science platforms that 
could be of benefit. These may help to further breakdown some of the negative barriers that remain between scientific professionals and amateur volunteers. The following section will summarise how citizen science may be able to learn from the creative communities they share the web with, as well as highlighting those areas where this is still not feasible or desirable. It is important to remember that not all barriers to professional practice necessarily need to be broken down, as evidenced by the beneficial nature of infrastructure and accreditation in science.

In citizen science, acknowledgement between professionals and amateurs tends to be much more generalised than is found in webcomic communities. Often thanks is given by professionals to the amateur community as a whole rather than individually. In some rare cases, amateurs who engage the most on the Zooniverse platform are rewarded through acknowledgement on papers, or are listed as co-authors [Lintott et al., 2009]. Whilst in general citizen scientists seem content in knowing they have played a small role in furthering scientific knowledge, lessons could be learnt from the webcomics approach, in which all professional and amateur contributions may be openly recognised as beneficial. More could be done regarding acknowledging individual contribution to the overall outcomes, and providing feedback on performance and impact tailored to each volunteer. This could assist with making citizen scientists feel more involved with the project and aware of their importance, which can provide motivation to participate [Raddick et al., 2013; Tiago et al., 2017].

The relationship between professionals and amateurs in the citizen science community is a more structured collaboration. The science team derives the problem to solve, releases the data on a platform of their design, and only then involves the amateur community with individual volunteers making a limited, controlled contribution [Woodcock et al., 2017]. Once analysis is complete, the professional science team study and refine the results to decide on any important findings to release. Traditional infrastructural support is still important, with recognised, self-supporting professionals with formal accreditation leading the communities. The advantage of such a relationship is in ensuring the science published is robust, and trusted by the scientific community as a whole. This is still needed, as many scientists are still reticent to acknowledge the contribution of citizen scientists to science [Golumbic et al., 2017]. Although there has been movement towards giving citizen scientists a greater influence [Crowston, Mitchell and Østerlund, 2018], the webcomics example can be learnt from. By opening up more of the scientific process to volunteers, reducing some of the formal infrastructure and allowing them to contribute to the formation of scientific cases and conclusions, a more engaged and informed community could result.

However, infrastructural support is also an area where creative communities may learn from citizen science. In webcomics, whilst there is no longer a need for a traditional publisher or distribution company, giving much greater freedom to succeed, the dedication required in traditional professional infrastructures is still highly visible. The increased freedom has also led to a flood of content that makes becoming noticed very difficult. This may also lead to problems for audiences who find it hard to locate the high quality work amongst the constant stream of content. Practices from the scientific community, particularly citizen science, where validation of good work, for example through publication in peer-reviewed journals, is still very much a part of the online infrastructure, could be beneficial to creators. 
Whilst the emphasis for interaction with audiences in the webcomics community is firmly on social media, creators still maintain their own homepages for their comics, and need to drive viewers there or to a merchandise platform in order to make money. This shows the continuing benefit of platform specialisation to the professional, and echoes the hosting of many different citizen science projects across the Zooniverse. Such platforms provide greater control over content and can help with issues of quality control: artists working with recognised publishing platforms are signalling they are of professional quality and readers can find them more easily.

Citizen science is still highly structured around their own specially-designed platforms both for completing their research aims and for communication. However, the problem with such a model is the creation of an echo chamber, with amateurs only communicating with professionals and other amateurs already engaged with the project. By adopting an approach more akin to the webcomics community, involving greater two-way communication on social media platforms, a larger audience could be reached and encouraged to take part. This larger reach could also be applied to broadening the demographics of the community, an issue that requires further investment in the citizen science domain [Newman et al., 2012].

This paper describes two very small studies of very specific example communities. The overall aim was to explore how amateurs and professionals in varied domains may be able to learn from each other to improve their interactions. The nature of the method does mean that generalisation to other communities may be difficult, and larger, more rigorous studies, and studies of other communities would be beneficial. In terms of citizen science, future research could continue extend the dialogue by looking at other types of citizen science communities who are more based in the field, compared to different creative processes that are also more reliant on the offline world, for example music. The method, in which specific themes identified in the first study were applied to the second, also has its limitations, as interesting aspects of both practices may have been missed. Applying a more open approach to the second study would have allowed additional themes to be identified which could then have been iteratively applied to the results of the first study. However, as a small study intended to begin a continuing exploration of practices, these three themes appeared to be the most relevant, and evoked some interesting points.

\section{Conclusions}

There are some clear potential lessons that citizen science practices can learn from the webcomics example. In the realm of mutual acknowledgement, more could be done in terms of recognising each individual contribution, rather than only 'super-users' who may become co-authors of the work. This could be achieved through further infrastructural support, allowing the volunteer greater access to the scientific process. Although some more recent projects have provided tools that allow volunteers access to more of the process (Galaxy Zoo), and even created online courses to help bridge the gap between the formal training of scientific experts and volunteers (growobservatory.org), the science team still control the overall scientific case and ultimately how the analysis is aggregated and disseminated. Allowing the amateur citizen scientist more influence in this process could increase their feeling of worth, intrinsically supplying an acknowledgement of their contribution. Additionally, more could be done by citizen science platforms 
to harness the potential of social media platforms. Although there are examples of smaller, short-term citizen science projects making wider use of social media [Liberatore et al., 2018], the majority rely on purposely built platforms. Whilst platform specialisation is important to control and legitimise the scientific approach, the webcomics community has demonstrated how social media can be a powerful tool in creating an engaged amateur community. It could also help diversify the citizen scientist demographic, reaching out to members of society that perhaps would not normally visit a specialised citizen science platform directly.

Where the distinction between professionals and amateurs was once clear, the adoption of online services by each puts these distinctions into question. By exploring the practices of two distinct communities, we have shown how collaborations online are not only expanding the scope for amateur practice but also blurring the boundaries between professionals and amateurs. Whilst this is predominantly seen as positive, it is important to consider the potential negative consequences, as well as whether it is desirable for particular careers. For example, in the creative industries, moving online allows far more creators the opportunity to become professional (or at least to work to a professional standard) but it may also lead to a flooding of the market in which highly skilled people get lost. In the realm of scientific research, whilst increased collaboration and encouragement of amateur scientists is highly beneficial to both professional and amateurs, some form of infrastructural control ensures the science produced makes a real contribution to furthering research.

More research is needed into the use of digital platforms by professional and amateur users across varying domains, as well as more consideration of the potential issues in blurring or removing barriers to professional practice. Specifically within citizen science, mechanisms that further citizen scientist involvement beyond the collection and analysis of data, to include interpretation and even follow-up hypothesis derivation should be explored. Building on this, understanding their effect on the relationship between professional and amateur, and how this is communicated through both the specific platform and social media could help inform better design and co-ordination. Ultimately, the next generation of citizen science projects could increase volunteer involvement throughout the scientific method, and it is yet to be seen if the scientific domain is ready to accept research from such sources, where the line between the amateur and professional contribution is not clearly stated.

\section{References}

Bonney, R., Cooper, C. B., Dickinson, J., Kelling, S., Phillips, T., Rosenberg, K. V. and Shirk, J. (2009). 'Citizen Science: a Developing Tool for Expanding Science Knowledge and Scientific Literacy'. BioScience 59 (11), pp. 977-984. https://doi.org/10.1525/bio.2009.59.11.9.

Cooper, C. B., Shirk, J. and Zuckerberg, B. (2014). 'The Invisible Prevalence of Citizen Science in Global Research: Migratory Birds and Climate Change'. PLOS ONE 9 (9), e106508. https://doi .org/10.1371/journal.pone. 0106508.

Crowston, K., Mitchell, E. and Østerlund, C. (2018). 'Coordinating advanced crowd work: extending citizen science'. In: Proceedings of the 51st Hawaii International Conference on System Sciences. ACM, pp. 1681-1690.

https://doi.org/10.24251/hicss.2018.212. 
Dobat, A. S. and Jensen, A. T. (2016). "'Professional amateurs". Metal detecting and metal detectorists in Denmark'. Open Archaeology 2 (1).

https://doi.org/10.1515/opar-2016-0005.

Dowthwaite, L. (2015). 'When things go wrong, when things go right: meaningful interactions between webcomics creators and readers'. In: Electricomics 2015 (University of Hertfordshire, Hatfield, U.K. 14th October 2015).

Dowthwaite, L., Houghton, R. J. and Mortier, R. (2015). 'Fame or function? How webcomic artists choose where to share'. In: Contemporary issues in ergonomics and human factors 2015. Ed. by S. Sharples, S. Shorrock and P. Waterson. London, U.K.: Taylor \& Francis, pp. 355-362.

Eveleigh, A. M. M., Jennett, C., Blandford, A., Brohan, P. and Cox, A. L. (2014). 'Designing for dabblers and deterring drop-outs in citizen science'. In: Proceedings of the IGCHI Conference on Human Factors in Computing Systems (CHI '14). New York, NY, U.S.A.: ACM Press, pp. 2985-2994. https://doi.org/10.1145/2556288.2557262.

Fenty, S., Houp, T. and Taylor, L. (2004). 'Webcomics: the influence and continuation of the comix revolution'. ImageTexT: Interdisciplinary Comics Studies 1 (2). URL: ht tp://www. english.ufl. edu/imagetext/archives/v1_2/group/index.shtml.

Glaser, B. and Strauss, A. L. (1967). The discovery of grounded theory: strategies for qualitative research. Chicago, IL, U.S.A.: Aldine.

Golumbic, Y. N., Orr, D., Baram-Tsabari, A. and Fishbain, B. (2017). 'Between vision and reality: a case study of scientists' views on citizen science'. Citizen Science: Theory and Practice 2 (1), p. 6. https: //doi.org/10.5334/cstp. 53.

Guigar, B., Kurtz, S. R., Kellett, D. and Straub, K. (2011). How to make webcomics. Berkeley, CA, U.S.A.: Image Comics.

Hand, E. (2010). 'Citizen science: people power'. Nature 466 (7307), pp. 685-687. https://doi.org/10.1038/466685a.

Hoare, M., Benford, S., Jones, R. and Milic-Frayling, N. (2014). 'Coming in from the margins: amateur musicians in the online age'. In: Proceedings of the 32nd annual ACM conference on Human factors in computing systems - CHI '14 (Toronto, Canada). ACM, pp. 1295-1304. https://doi.org/10.1145/2556288.2557298.

Jackson, C. B., Crowston, K., Mugar, G. and Østerlund, C. (2016). "“Guess what! You're the first to see this event"'. In: Proceedings of the 19th International Conference on Supporting Group Work - GROUP '16 (Sanibel Island, FL, U.S.A.). ACM, pp. 171-179. https://doi.org/10.1145/2957276.2957284.

Johnston, S. F., Franks, B. and Whitelaw, S. (2017). 'Crowd-sourced science: societal engagement, scientific authority and ethical practice'. Journal of Information Ethics 26 (1), pp. 49-65.

Kaplan, M. (1960). Leisure in America. New York, NY, U.S.A.: John Wiley \& Sons.

Kuznetsov, S. and Paulos, E. (2010). 'Rise of the expert amateur: DIY projects, communities and cultures'. In: Proceedings of the 6 th Nordic Conference on Human-Computer Interaction Extending Boundaries - NordiCHI '10 (New York, NY, U.S.A.). ACM, pp. 295-304. https : //doi .org/10.1145/1868914.1868950.

Leadbeater, C. and Miller, P. (2004). The pro-am revolution: how enthusiasts are changing our economy and society. London, U.K.: Demos.

Lessig, L. (2009). Remix: making art and commerce thrive in the hybrid economy. New York, NY, U.S.A.: Penguin Books.

- (2012). 'REMIX: how creativity is being strangled by the law'. In: The social media reader. Ed. by M. Mandiberg. New York, NY, U.S.A.: New York University Press, pp. 155-170. URL: http://klangable.com/uploads/books/Ma ndiberg-theSocialMediaReader-cc-by-sa-nc.pdf. 
Leyshon, A., Webb, P., French, S., Thrift, N. and Crewe, L. (2005). 'On the reproduction of the musical economy after the Internet'. Media, Culture $\mathcal{E}$ Society 27 (2), pp. 177-209. https : //doi .org/10.1177/0163443705050468.

Liberatore, A., Bowkett, E., MacLeod, C. J., Spurr, E. and Longnecker, N. (2018). 'Social media as a platform for a citizen science community of practice'. Citizen Science: Theory and Practice 3 (1). https://doi .org/10.5334/cstp. 108.

Lintott, C. J., Schawinski, K., Keel, W., Arkel, H. van, Bennert, N., Edmondson, E., Thomas, D., Smith, D. J. B., Herbert, P. D., Jarvis, M. J., Virani, S., Andreescu, D., Bamford, S. P., Land, K., Murray, P., Nichol, R. C., Raddick, M. J., Slosar, A., Szalay, A. and Vandenberg, J. (2009). 'Galaxy Zoo: 'Hanny's Voorwerp', a quasar light echo?' Monthly Notices of the Royal Astronomical Society 399 (1), pp. 129-140. https://doi.org/10.1111/j.1365-2966.2009.15299.x.

Makimoto, T. and Manners, D. (1997). Digital nomad. New York, NY, U.S.A.: John Wiley \& Sons.

Masters, K., Oh, E. Y., Cox, J., Simmons, B., Lintott, C., Graham, G., Greenhill, A. and Holmes, K. (2016). 'Science learning via participation in online citizen science'. JCOM 15 (3), A07.

URL: https://jcom.sissa.it/archive/15/03/JC0M_1503_2016_A07.

McCloud, S. (2000). Reinventing Comics: How Imagination and Technology Are Revolutionizing an Art Form. U.S.A.: Harper Collins.

Newman, G., Wiggins, A., Crall, A., Graham, E., Newman, S. and Crowston, K. (2012). 'The future of citizen science: emerging technologies and shifting paradigms'. Frontiers in Ecology and the Environment 10 (6), pp. 298-304. https://doi.org/10.1890/110294.

Nicey, J. (2016). 'Semi-professional amateurs'. In: The SAGE Handbook of Digital Journalism. Ed. by T. Witschge, C. W. Anderson, D. Domingo and A. Hermida. U.K.: SAGE, pp. 222-235. https://doi .org/10.4135/9781473957909.n15.

Oppenheim, A. N. (2000). Questionnaire design, interviewing and attitude measurement. U.K.: Bloomsbury Publishing.

Penston, M. (2001). 'Pro-Am astronomy'. Astronomy and Geophysics 42 (1), pp. 1.31-1.32. https://doi.org/10.1046/j.1468-4004.2001.0420011.31.x.

Ploderer, B., Howard, S. and Thomas, P. (2010). 'Collaboration on social network sites: amateurs, professionals and celebrities'. Computer Supported Cooperative Work (CSCW) 19 (5), pp. 419-455. https://doi.org/10.1007/s10606-010-9112-0.

Prior, N. (2014). 'The rise of the new amateurs'. In: Handbook of cultural sociology. Ed. by L. Grindstaff, M.-C. M. Lo and J. R. Hall. U.K.: Routledge. https://doi.org/10.4324/9780203891377.ch38.

Raddick, M. J., Bracey, G., Gay, P. L., Lintott, C. J., Cardamone, C., Murray, P., Schawinski, K., Szalay, A. S. and Vandenberg, J. (2013). 'Galaxy Zoo: Motivations of Citizen Scientists'. Astronomy Education Review 12 (1), pp. 010106-010101. https://doi.org/10.3847/AER2011021. arXiv: 1303.6886.

Reed, J., Rodriguez, W. and Rickhoff, A. (2012). 'A framework for defining and describing key design features of virtual citizen science projects'. In: Proceedings of the 2012 iConference - iConference '12 (Toronto, Canada), pp. 623-625. https://doi.org/10.1145/2132176.2132314.

Rohac, G. (2010). 'Copyright and the economy of webcomics'. Master's thesis. New York, NY, U.S.A.: New York University. 
Roibás, A. C. and Sala, R. (n.d.). 'Beyond mobile TV: understanding how mobile interactive systems enable users to become digital producers'. In: Human-Computer Interaction. HCI Intelligent Multimodal Interaction Environments - HCI '07. Berlin, Heidelberg, Germany: Springer-Verlag, pp. 801-810. https://doi.org/10.1007/978-3-540-73110-8_87.

Simpson, R., Page, K. R. and De Roure, D. (2014). 'Zooniverse: observing the World's Largest Citizen Science Platform'. In: Proceedings of the 23rd International Conference on World Wide Web - WWW'14 Companion (Seoul, Korea, 7th-11th April 2014). ACM Press, pp. 1049-1054. https://doi.org/10.1145/2567948.2579215.

Sprinks, J., Houghton, R., Bamford, S. and Morley, J. (2015). 'Citizen scientists: the importance of being needed and not wasted'. In: Proceedings of CHI PLAY '15 Workshop: the annual symposium on Computer-Human Interaction in Play (London, U.K.). ACM, p. 3.

Stebbins, R. A. (1992). Amateurs, professionals and serious leisure. Montreal, QC, Canada: McGill-Queen's University Press. URL: https://www.jstor.org/stable/j.ctt81ccj.

Strachan, R. (2007). 'Micro-independent record labels in the U.K.: discourse, DIY cultural production and the music industry'. European Journal of Cultural Studies 10 (2), pp. 245-265. https: //doi .org/10.1177/1367549407075916.

Tanenbaum, J. G., Williams, A. M., Desjardins, A. and Tanenbaum, K. (2013). 'Democratizing technology: Pleasure, utility, and expressiveness in DIY and maker practice'. In: Proceedings of the SIGCHI Conference on Human Factors in Computing Systems (CHI '13) (Paris, France, 27th April-2nd May 2013). ACM Press, pp. 2603-2612. https://doi.org/10.1145/2470654.2481360.

Tiago, P., Gouveia, M. J., Capinha, C., Santos-Reis, M. and Pereira, H. M. (2017). 'The influence of motivational factors on the frequency of participation in citizen science activities'. Nature Conservation 18, pp. 61-78. https://doi.org/10.3897/natureconservation.18.13429.

Torrey, C., Churchill, E. F. and McDonald, D. W. (2009). 'Learning how: the search for craft knowledge on the Internet'. In: Proceedings of the 27th international conference on Human factors in computing systems - CHI '09 (Boston, MA, U.S.A.). ACM, pp. 1371-1380. https://doi.org/10.1145/1518701.1518908.

Trumbull, D. J., Bonney, R., Bascom, D. and Cabral, A. (2000). 'Thinking scientifically during participation in a citizen-science project'. Science Education 84 (2), pp. 265-275. https: //doi .org/10.1002/ (SICI) 1098-237X (200003) 84:2 <265: :AID-SCE7>3.0.CO;2-5.

Wiggins, A. and Crowston, K. (2011). 'From Conservation to Crowdsourcing: a Typology of Citizen Science'. In: Proceedings of the $44^{\text {th }}$ Hawaii International Conference on System Sciences (HICSS-44). Kauai, HI, U.S.A. Pp. 1-10. https://doi.org/10.1109/HICSS .2011.207.

Woodcock, J., Greenhill, A., Holmes, K., Graham, G., Cox, J., Oh, E. Y. and Masters, K. (2017). 'Crowdsourcing citizen science: exploring the tensions between paid professionals and users'. Journal of Peer Production.

URL: http://peerproduction.net/issues/issue-10-peer-production-and-w ork/peer-reviewed-papers/crowdsourcing-citizen-science-exploring-th e-tensions-between-paid-professionals-and-users/. 
Zevin, M., Coughlin, S., Bahaadini, S., Besler, E., Rohani, N., Allen, S., Cabero, M., Crowston, K., Katsaggelos, A. K., Larson, S. L., Lee, T. K., Lintott, C., Littenberg, T. B., Lundgren, A., Østerlund, C., Smith, J. R., Trouille, L. and Kalogera, V. (2017). 'Gravity Spy: integrating advanced LIGO detector characterization, machine learning, and citizen science'. Classical and Quantum Gravity 34 (6), p. 064003. https://doi .org/10.1088/1361-6382/aa5cea.

Authors

Dr Liz Dowthwaite is a researcher in the Horizon Digital Economy Research Institute at the University of Nottingham with a multi-disciplinary research background grounded in Psychology and Human Factors. Her research interests include individual behaviour in online crowd systems, including crowdfunding and citizen science, especially the roles of incentives and reciprocal motivations for participation; outreach and science communication, especially engaging with young people; and the effects of the online world on psychological well-being. E-mail: liz.dowthwaite@nottingham.ac.uk.

Dr James Sprinks is a Research Fellow in the School of Science and Technology at Nottingham Trent University. His research considers the use of Citizen Science to identify and map geomorphological features on the surface of Mars. He is researching how citizen science platforms can be designed and implemented to both ensure that the data generated is in a usable format and scientifically robust, while still maintaining a user experience that results in volunteers enjoying and learning from the process. This process encompasses elements of planetary science, remote sensing, Human-Computer Interaction, GIS, ergonomics and human factors research. E-mail: james.sprinks@ntu.ac.uk.

\section{How to cite}

Dowthwaite, L. and Sprinks, J. (2019). 'Citizen science and the professional-amateur divide: lessons from differing online practices'. JCOM 18 (01), A06. https:/ / doi.org/10.22323/2.18010206. 